\title{
Obesity indices as predictive factors for paediatric hypertension: A population-based study in Bali, Indonesia
}

\author{
*Dyah Kanya Wati ${ }^{1}$, I Gusti Lanang Sidiartha ${ }^{1}$ \\ Sri Lanka Journal of Child Health, 2022; 51(1): 20-28 \\ DOI: http://dx.doi.org/10.4038/sljch.v51i1.9988
}

\begin{abstract}
Introduction: Growing recognition of coexisting obesity and hypertension epidemics in children and adolescents could prevent it from being an insurmountable burden following its trajectory into adulthood.
\end{abstract}

Objectives: To determine the predictive ability of obesity indices for paediatric hypertension.

Method: In this retrospective cross-sectional study, a multi-stage sampling method was employed to recruit proportional population-based samples across Bali, Indonesia. A total of 436 students aged 6-17 years who had no prior history of hypertension / prolonged use of drugs affecting blood pressure were included in the analysis. Nutritional status assessment warranted a two-step assessment using weight-for-height and body mass index (BMI)-forage CDC 2000 charts for each gender. Bivariate and multivariate analyses were done to find associated factors. Receiver operating characteristic (ROC) curve analysis was done to assess the predictive ability of waist circumference.

Results: In this study there were 229 children with hypertension. The prevalence of overweight $(14.7 \%)$ and obesity $(40.8 \%)$ in hypertensive students was greater than the overall overweight $(13.1 \%)$ and obesity (32.8\%) prevalence. Age, nutritional status and waist circumference were significantly increased in the group with hypertension on bivariate analysis. After multivariate analysis, increasing age (prevalence ratio [PR] 1.106; 95\%CI 1.015-1.205) and obesity (PR 2.174; 95\%CI 1.371-3.445) were significantly associated with hypertension but not waist

${ }^{1}$ Paediatric Consultant, Department of Child Health, Faculty of Medicine, Universitas Udayana / Sanglah General Hospital, Denpasar, Bali, Indonesia

*Correspondence: dyahkanyawati@unud.ac.id

https//orcid.org/ 0000-0002-6633-7445

(Received on 19 December 2020: Accepted after revision on 19 February 2021)

The authors declare that there are no conflicts of interest

Personal funding was used for the project.

Open Access Article published under the Creative

Commons Attribution CC-BY (c) (i) License circumference. Optimal cut-off points for male (65.5 $\mathrm{cm})$ and female $(62.5 \mathrm{~cm})$ waist circumference were obtained.

Conclusions: Obesity status and waist circumference served as promising predictors of hypertension.

(Key words: Paediatric hypertension, Abdominal obesity, Waist circumference, Indonesia)

\section{Introduction}

Over the past two decades, there was a consistent increase in the prevalence of hypertension in children and adolescents with similar age-specific rates. The rise was nearly exponential across each decade of study period, reaching a prevalence of $6 \%$ by 2014 with pooled prevalence of $4 \%{ }^{1,2}$. Combined prevalence of elevated blood pressure and hypertension summed up to a total exceeding $10 \%$ cases which may potentially follow this adverse trajectory into adulthood ${ }^{3,4}$. Additionally, a recent study indicated the long-term impact of elevated blood pressure on cardiovascular disease intermediate markers in adulthood ${ }^{5}$.

The concurrent obesity epidemic yields a remarkable contribution to the burden of noncommunicable disease in the paediatric population, given its mechanistic relationship with hypertension as a metabolic syndrome cluster ${ }^{6}$. The prevalence of hypertension in obese children and adolescents was markedly higher $(15.3 \%)$ than the non-obese counterpart $^{1}$. Additionally, proportional increment in the risk of developing hypertension was observed with increasing nutritional status ${ }^{7}$. The seemingly bidirectional association of obesity and hypertension was appraised by a meta-analysis which reported the association between childhood obesity and multiple obesity-related morbidities in adulthood ${ }^{8}$.

Although the relationship between obesity and hypertension in childhood and adolescence was well-established $^{9,10}$, the data on discriminatory power among obesity indices was lacking ${ }^{11}$ and heterogeneous $^{8,12}$ in available evidence. Furthermore, the difference in guidelines being adopted to define each disease entity in certain areas, specifically in Indonesia, requires standardized study methods specifically tailored to each population. Addressing the aforementioned research gap is of utmost importance considering its 
prospective implication on hypertension and obesity guideline development and implementation ${ }^{13}$, and lifetime risks adjustment ${ }^{14,15}$ in which the contribution from the paediatric population was not commonly accounted for.

\section{Objectives}

The primary objectives were to investigate the association between obesity indices with hypertension and identify the optimal cut-off point for waist circumference to predict hypertension.

\section{Method}

This study was a provincial, population-based, retrospective, cross-sectional study held in Bali, Indonesia. We used the database from previous study ${ }^{16}$ which aimed to investigate blood pressure profile in children and adolescents with distinct methods in terms of study design, eligibility criteria,

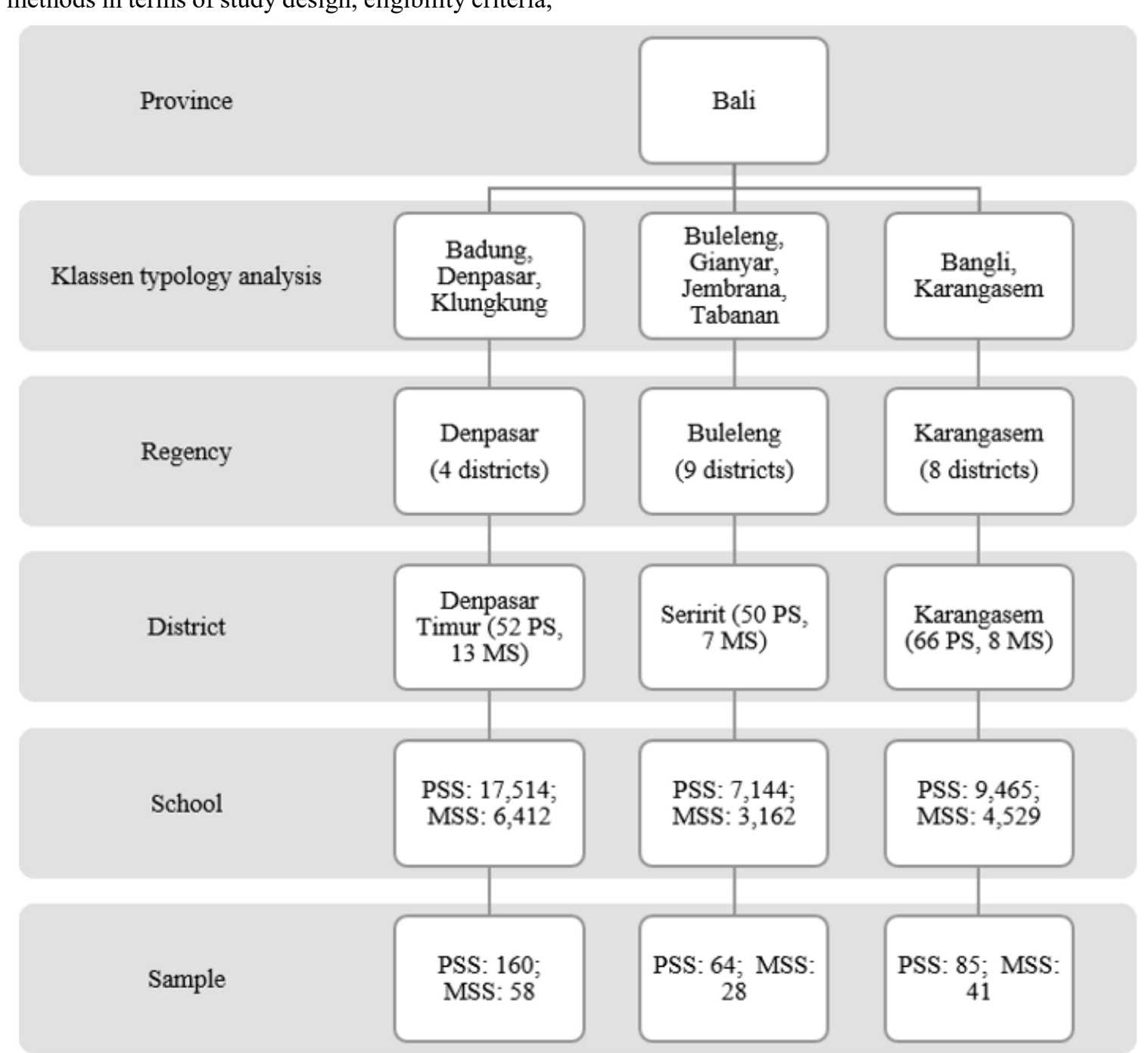

Figure 1: Schematic flow of multi-stage sampling method

MS: middle school, MSS: middle school student, PS: primary school, PSS: primary school student

Initially, nine regencies in Bali were classified into three groups of economic growth structure and pattern according to Klassen typology analysis, and outcomes. The study population was considered otherwise healthy because we utilized a sampling frame consisting of general student population.

Ethical issues: Our study fully adhered to the Declaration of Helsinki and its subsequent amendments and was approved by the Ethical Committee of the Medical Faculty of Udayana University/Sanglah General Hospital (No. 1634/UN14.2.2/PD/KEP/2018) Preliminary consent from local school administrators and parents or legal guardians, as well as assent from students were obtained before study commencement.

We employed a multi-stage sampling technique to select regencies, districts, schools, and ultimately students who were eligible for recruitment (Figure $1)$. 
relatively underdeveloped (Bangli, Karangasem) ${ }^{17}$. Simple random sampling was done to choose the regency, district, schools, and students using random number generator and select case feature in IBM SPSS ${ }^{\circledR}$ statistical analysis software. A predetermined sample size was allocated to proportionally match the ratio of total students in selected districts and subsequently, the ratio of primary and middle school students in each regency based on Ministry of Education and Culture reference data ${ }^{18}$. Estimated sample size was calculated using StatCalc feature in Epi Info ${ }^{\text {TM }}$ version 7.2 with $80 \%$ statistical power and outcome percentage derived from the previous metaanalysis ${ }^{1}$.

The 2019 baseline data were collected from 1,257 students of 18 schools who fulfilled the determined eligibility criteria. We included children aged 6 to 18 years at the time of enrolment, whose parents or legal guardians agreed to provide written informed consent. Subjects who failed to complete the study procedure or had a previous history of prolonged $(>2$ weeks) use of corticosteroids or other drugs that affect blood pressure were excluded. Data regarding clinical assessment of students and their parents or legal guardians were obtained through a structured interview using questionnaire and direct measurement of key variables. The current analysis focused on sociodemographic characteristics and key variables (i.e. blood pressure, anthropometric measures) of 436 students.

Nutritional and hypertension status assessment involved the measurement of body weight, body height, waist circumference and blood pressure by trained health personnel (doctors) using standardized procedures and calibrated equipment. Weight was measured using flat digital scale (precision $0.1 \mathrm{~kg}$ ), height was measured using portable stadiometer (precision $0.1 \mathrm{~cm}$ ), waist circumference was measured using a tape (precision $0.1 \mathrm{~cm}$ ), and blood pressure was measured using aneroid sphygmomanometer. Body mass index was calculated by dividing weight in kilogrammes with the square of height in metres.

Nutritional status was categorized in compliance with the Indonesian Paediatric Society recommendation on paediatric nutrition care $^{19}$. Generally, all students were subjected to Waterlow criteria for the percentage of median weight-forheight plotted using Centers for Disease Control and Prevention (CDC) 2000 growth charts. Overweight or obesity in students with the percentage of median above $110 \%$ would be determined by CDC 2000 body mass index (BMI)-for-age chart (Table 1).

Table 1: Nutritional status assessment of over 5 year old children ${ }^{19}$

\begin{tabular}{|l|c|c|}
\hline \multicolumn{1}{|c|}{ Nutritional status } & Weight for height (\% median) & Body mass index for age \\
\hline Obese & $>120$ & $>95$ th percentile \\
\hline Overweight & $>110$ & 85th to 95th percentile \\
\hline Normal & $>90$ & \\
\hline Underweight & $70-90$ & \\
\hline Wasted & $<70$ & \\
\hline
\end{tabular}

Overweight and obese statuses were collectively termed over-nutrition whilst underweight and wasted were collectively referred to as undernutrition. Obesity indices consisted of nutritional status to determine obesity in general and waist circumference to determine abdominal obesity. Meanwhile, hypertension status was assessed by categorizing the average of three blood pressure measurementss using clinical practice guideline developed by the American Academy of Pediatrics $^{20}$.

Continuous variables were presented in appropriate central tendency and dispersion (i.e., median [interquartile range (IQR)] or mean $[ \pm$ standard deviation (SD)]) depending on the result of Kolmogorov-Smirnov normality test, whereas categorical variables were presented as absolute and relative frequency. Mann-Whitney and Chi-square tests were done preceding multivariable logistic regression analysis incorporating correlated variables with $\mathrm{p}$ values less than 0.1 . Predictive ability was assessed using receiver operating characteristic (ROC) curve analysis and interpreted accordingly with respect to the indices generated. All statistical analyses were performed using IBM SPSS ${ }^{\circledR}$ version 25 with two-sided $p$ value of $<0.05$ being considered as statistically significant.

\section{Results}

Three regencies and districts were chosen from the first and second cluster sampling. From the total number of students in each district, randomly sampled 1,257 students from 18 schools were included in the initial investigation and 436 of them were included in current analysis (Figure 1). The proportion of students was allotted considering the ratio of students in each district for each level (i.e., primary or middle school).

The overall prevalence of over-nutrition was highest in Denpasar (54.1\%), followed by Karangasem $(47.2 \%)$ and Buleleng (30.1\%) regency. A relatively unimodal trend in total prevalence was observed 
over increasing age with the peak at 11 years, except for higher figures at both extremes of age, which may not represent actual values due to inadequate subjects. Although the peak for Buleleng (12.5\%) and Karangasem (34.4\%) regencies coincided with that of the total, the peak prevalence for Denpasar $(52.9 \%)$ was situated at 13 years old (Figure 2$)$.

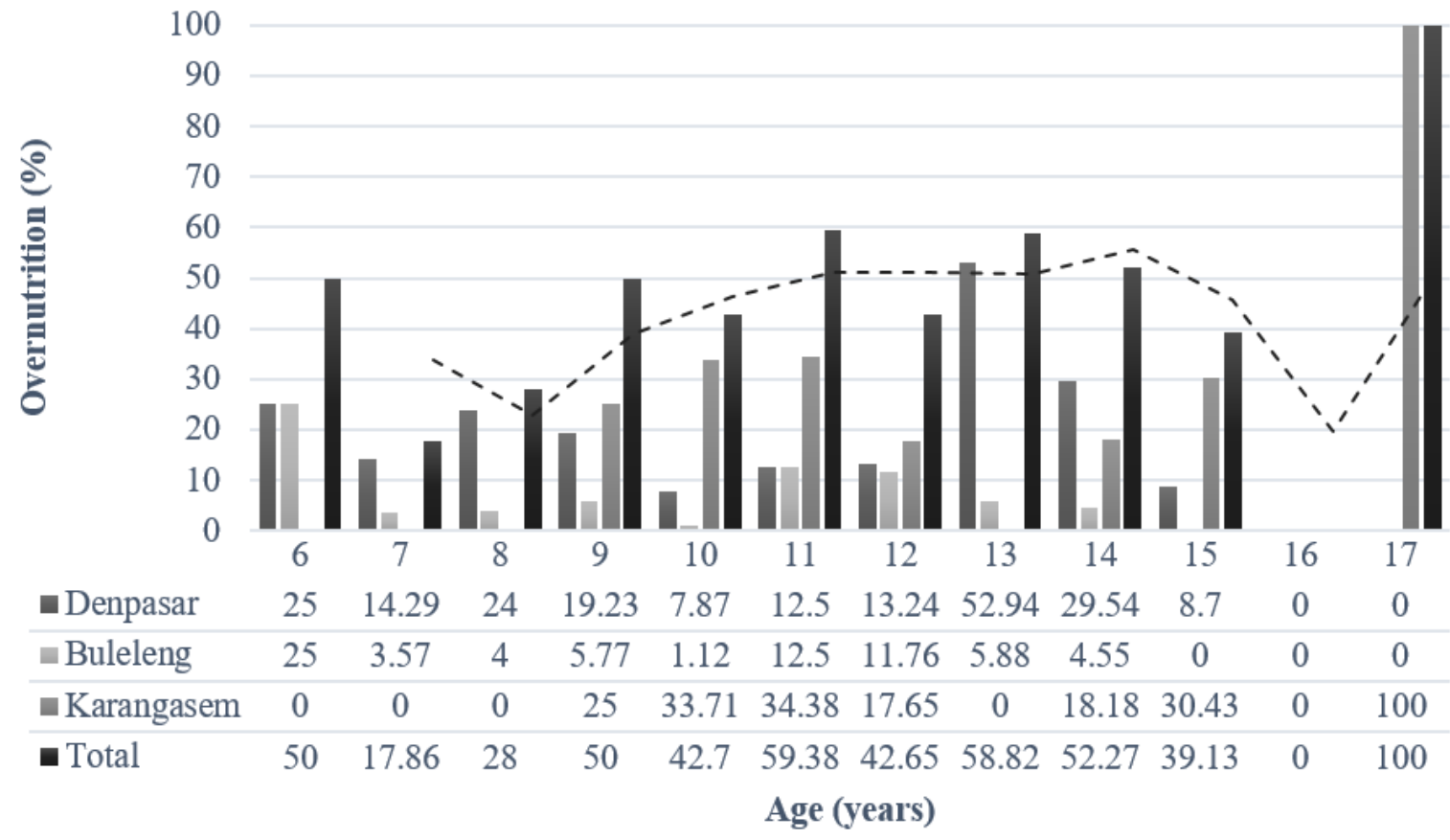

Figure 2: Prevalence of over-nutrition based on age and regency

The prevalence of hypertensive individuals exceeded normotensive individuals in obese and overweight students and not in the other nutritional statuses. It was notable that the ratio between hypertensive and normotensive students increased with increasing nutritional status in students with over-nutrition (Figure 3).

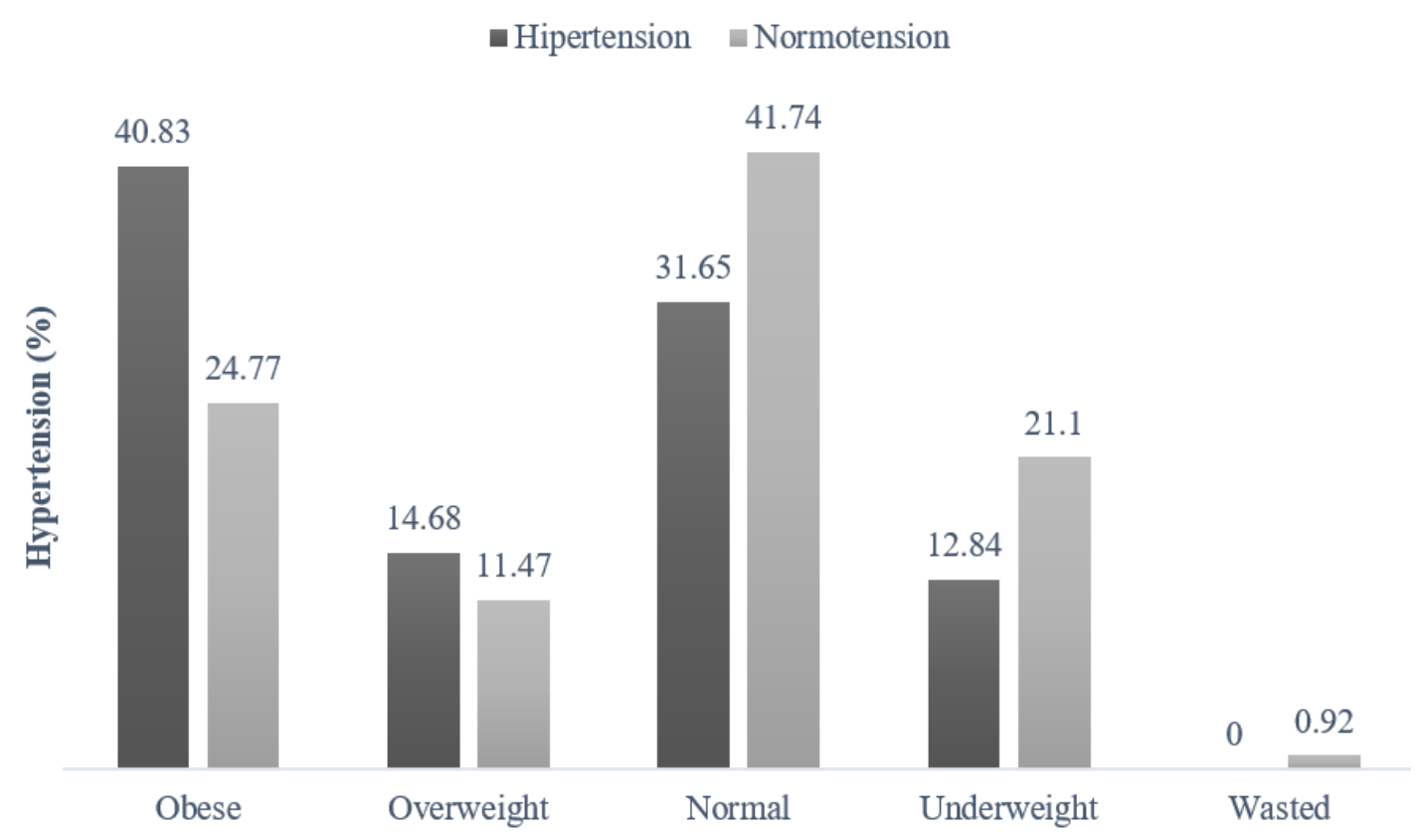

Figure 3: Prevalence of hypertension based on nutritional status 
The students had a median age of 11 years (IQR 912) and median waist circumference of $65 \mathrm{~cm}$ (IQR 59-75). The majority of students were indigenous males with normal nutritional status. Bivariate analysis in Table 2 showed that apart from nutritional status and waist circumference, age was statistically significant and should be included in multivariate analysis.

Table 2: Demographics of study subjects

\begin{tabular}{|l|c|c|}
\hline \multicolumn{1}{|c|}{ Variables } & Result & p \\
\hline Gender & & 0.387 \\
Male - n (\%) & $237(54.4)$ & \\
Female - n (\%) & $199(45.6)$ & $\mathbf{0 . 0 1 4}$ \\
\hline Age* - Median (IQR) & $11(9-12)$ & 0.630 \\
\hline Origin & $418(95.9)$ & $\mathbf{0 . 0 0 1}$ \\
Bali - n (\%) & $18(04.1)$ & \\
Outside Bali - n (\%) & $143(32.8)$ & \\
\hline Nutritional status & $57(13.1)$ & \\
Obese - n (\%) & $160(36.7)$ & \\
Overweight - n (\%) & $74(17.0)$ & \\
Normal - n (\%) & $02(0.5)$ & $<\mathbf{0 0 1}$ \\
Underweight - n (\%) & $65(59-75)$ & \\
Wasted - n (\%) & & \\
\hline Waist circumference*-Median (IQR) & & \\
\hline
\end{tabular}

*Based on Mann-Whitney test; bold indicates $p<0.05$; IQR: inter-quartile range;

Binomial logistic regression analysis showed obesity status (PR 2.174; 95\%CI 1.371-3.445) and age (PR 1.106; 95\%CI 1.015-1.205) as statistically significant factors for hypertension (Table 3). The prevalence ratio for the wasted nutritional status was failed to obtain due to the lack of wasted hypertensive student.

Table 3: Multivariable analysis of factors affecting hypertension status

\begin{tabular}{|l|c|c|c|}
\hline \multicolumn{1}{|c|}{ Variables } & Prevalence ratio (PR) & $\mathbf{9 5 \%}$ confidence interval & p \\
\hline Age & 1.106 & $1.015-1.205$ & $\mathbf{0 . 0 2 1}$ \\
\hline Nutritional status & & & $\mathbf{0 . 0 0 1}$ \\
Obese & 2.174 & $1.371-3.445$ & 0.092 \\
Overweight & 1.688 & $0.918-3.106$ & Reference \\
Normal & Reference & Reference & 0.446 \\
Underweight & 0.803 & $0.457-1.412$ & 0.999 \\
Wasted & - & - & 0.101 \\
\hline Waist circumference & 1.027 & $0,995-1,061$ & \\
\hline
\end{tabular}

bold indicates $p<0.05$

Waist circumference cut-off value of $65.5 \mathrm{~cm}$ provided the most balanced sensitivity $(60.6 \%)$ and specificity (61.5\%) from ROC curve analysis (area under the curve $[\mathrm{AUC}]=0.640,95 \% \mathrm{CI} 0.588-0.691$, $\mathrm{p}<0.001)$. The farthest point from the reference line for male (AUC $=0.660,95 \%$ CI $0.591-0.729$, $\mathrm{p}<0.001)$ with sensitivity $(69.9 \%)$ and specificity $(57 \%)$ corresponded to a cut-off value overlapping with that of the overall curve. The ideal cut-off value for female $(62.5 \mathrm{~cm})$ with similar sensitivity $(62.1 \%)$ and specificity $(55.8 \%)$ in the curve $(\mathrm{AUC}=0.612$, $95 \%$ CI $0.533-0.690, \mathrm{p}=0.007)$ was lower than that of overall and male (Figure 4).

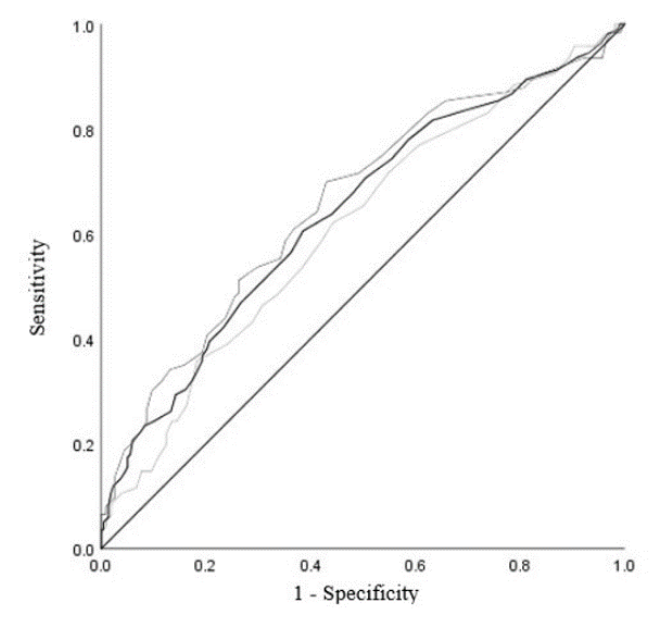

Figure 4. ROC curves for the prediction of hypertension by waist circumference (Overall, male, and female curves in decreasing opacity, respectively) 


\section{Discussion}

The rising trend of obesity worldwide is worthy of serious public health attention, chiefly in the younger population. This especially holds true in the provincial scale of Bali because its prevalence of overweight and obesity in children and adolescents $(21.9 \%)$ by $2018^{21}$ was greater than 2016 global estimates by World Health Organization $(18 \%)^{22}$. The presence of obesity results in the propensity for numerous comorbidities clustered in metabolic syndrome, including hypertension. Moreover, obesity per se was implicated in the risk of kidney injury, and even at a greater extent when combined with hypertension ${ }^{23}$. Decision to intervene at such a young age requires rigorous research to generate the expected well-grounded evidence.

Earnest efforts to address the long-standing issue of undernutrition in Indonesia had been pursued relentlessly since a dedicated national movement was implemented ${ }^{24}$. Results from the current study showed that the prevalence of over-nutrition was higher than undernutrition, and that its association with hypertension was significant. Despite facing the double burden of malnutrition (i.e. undernutrition and over-nutrition), it was clear from the epidemiological point of view that the scale of over-nutrition related problem outgrew the undernutrition counterpart and the covert tendency of health problems inflicted by over-nutrition should not render it less urgent.

A clear-cut trend of obesity prevalence with increasing age was not found in this study. Conversely, the increasing prevalence with advancing age was observed in an earlier national estimate in the United States (US ${ }^{25}$. However, the US estimate grouped the subjects into age groups with wide ranges, and it involved younger preschool children (2-5 years). Establishment of prevalence by age would allow for direct comparison with similar obesity-related comorbidities, thus pinpointing the age group at risk to prioritise.

From a previous study in the same site, the prevalence of hypertension in the age group $\leq 12$ years was $47.3 \%$ and in the age group $>12$ years was $62.6 \%{ }^{16}$. There appeared to be an arguably exposure-response relationship between hypertension and nutritional status which was amplified with increasing BMI. The supporting rationale was because hypertension was more prevalent exclusively in over-nutrition and the prevalence increased more than twice (i.e. nonlinear increase) from overweight to obese. An excellent study with more extensive range of overnutrition status by Parker et $a l^{26}$ confirmed this relationship precisely with the finding that the risk of developing hypertension consistently increased in obese and severely obese individuals. A more profound quantification was reported in a study by Chorin $e t a l^{27}$ which found a concurrent increase in systolic $(10 \mathrm{mmHg})$ and diastolic $(3-4 \mathrm{mmHg})$ blood pressure for every unit increase in BMI of healthy teenagers.

In contrast to the covert characteristic of hypertension, the proposition for the use of waist circumference to screen for central obesity and ultimately hypertension offers the benefit of being an overt characteristic and feasibility in measurement and interpretation. The particular pitfall for this proposition was the absence of standardized cut-off or curves. While the waist circumference cut-off value to predict hypertension remained debatable, the most recent international study ${ }^{28}$ proposed to predict adult central obesity by childhood or adolescence waist circumference which corresponded to $\geq 90$ th percentile. Pooled age (assuming the median age in this study) and genderspecific cut-off values derived from studies ${ }^{28-30}$ associating waist circumference with hypertension in children or adolescents exhibited wide ranges of measure for male $(67.1-85.3 \mathrm{~cm})$ and female $(68.2-$ $76.1 \mathrm{~cm})$. The optimal cut-off values in this study were below these ranges even with comparable ROC analysis indices, suggesting that the heterogeneity was possibly due to ethnicity.

To the best of our knowledge, by searching for recent studies and comparing with existing systematic review ${ }^{31}$, this was the first study in Indonesia that employed two-steps of over-nutrition status determination recommended by the Indonesian Paediatric Society. This study also provided local data to contribute for future waist circumference cut-off value determination.

Our study has several limitations in our methods. Firstly, we did not consider multiple categories of the nominal variable when calculating the minimum sample requirement. Secondly, the current study design did not allow for a chronological analysis of causality.

\section{Conclusions}

Nutritional status and waist circumference held the potential to predict hypertension status in children and adolescents.

\section{References}

1. Song $\mathrm{P}$, Zhang Y, Yu J, Zha M, Zhu Y, Rahimi K, et al. Global prevalence of hypertension in children: A systematic review and meta-analysis. JAMA Pediatrics 2019; 173(12):1154-63. https://doi.org/10.1001/jamapediatrics.201 9.3310

PMid: 31589252 PMCid: PMC6784751 
2. Bell CS, Samuel JP, Samuels JA. Prevalence of hypertension in children: Applying the new American Academy of Pediatrics clinical practice guideline. Hypertension. 2019; 73(1):148-52. https://doi.org/10.1161/HYPERTENSION AHA.118.11673

PMid: 30571555 PMCid: PMC6291260

3. Falkner B. The childhood role in development of primary hypertension. American Journal of Hypertension 2018; 31(7):762-9.

https://doi.org/10.1093/ajh/hpy058

PMid: 29648569

4. Oh JH, Hong YM. Blood pressure trajectories from childhood to adolescence in paediatric hypertension. Korean Circulation Journal 2019; 49(3): 223-37. https://doi.org/10.4070/kcj.2018.0448 PMid: 30808073 PMCid: PMC6393321

5. Yang L, Magnussen CG, Yang L, Bovet $P$, $\mathrm{Xi}$ B. Elevated blood pressure in childhood or adolescence and cardiovascular outcomes in adulthood: A systematic review. Hypertension 2020; 75(4): 948-55. https://doi.org/10.1161/HYPERTENSION AHA.119.14168

PMid: 32114851

6. Kotsis V, Jordan J, Micic D, Finer N, Leitner DR, Toplak H, et al. Obesity and cardiovascular risk: A call for action from the European Society of Hypertension Working Group of Obesity, Diabetes and the High-risk Patient and European Association for the Study of Obesity: Part A: Mechanisms of obesity induced hypertension. Journal of Hypertension 2018; 36(7): 1427-40. https://doi.org/10.1097/HJH.00000000000 01731

7. Wühl E. Hypertension in childhood obesity. Acta Paediatrica International Journal of Paediatrics 2019; 108(1): 3743.

https://doi.org/10.1111/apa.14551

PMid: 30144170

8. Llewellyn A, Simmonds M, Owen CG, Woolacott N. Childhood obesity as a predictor of morbidity in adulthood: A systematic review and meta-analysis. Obesity Reviews 2016; 17(1): 56-67. https://doi.org/10.1111/obr.12316 PMid: 26440472
9. Fowokan AO, Sakakibara BM, Onsel N, Punthakee Z, Waddell C, Rosin M, et al. Correlates of elevated blood pressure in healthy children: a systematic review. Clinical Obesity 2018; 8(5): 366-81. https://doi.org/10.1111/cob.12271 PMid: 30066442

10. Díaz A, Calandra L. High blood pressure in school children and adolescents in Argentina over the past 25 years: A systematic review of observational studies. Archivos Argentinos Pediatria 2017; 115(1): 5-11.

https://doi.org/10.5546/aap.2017.eng.5 PMCid: PMC6250071

11. Lo K, Wong M, Khalechelvam P, Tam W. Waist-to-height ratio, body mass index and waist circumference for screening paediatric cardio-metabolic risk factors: A meta-analysis. Obesity Reviews 2016; 17(12): 1258-75.

https://doi.org/10.1111/obr.12473

12. Ma C, Wang R, Liu Y, Lu Q, Lu N, Tian Y, et al. Performance of obesity indices for screening elevated blood pressure in paediatric population: Systematic review and meta-analysis. Medicine (United States) 2016; 95(39).

https://doi.org/10.1097/MD.00000000000 04811

PMid: 27684808 PMCid: PMC5265901

13. Weaver DJ. Paediatric hypertension: Review of updated guidelines. Pediatrics in Review 2019; 40(7): 354-8. https://doi.org/10.1542/pir.2018-0014 PMid: 31263043

14. Vasan RS, Beiser A, Seshadri S, Larson MG, Kannel WB, D'Agostino RB, et al. Residual lifetime risk for developing hypertension in middle-aged women and men: The Framingham Heart Study. Journal of the American Medical Association 2002; 287(8): 1003-10. https://doi.org/10.1001/jama.287.8.1003 PMid: 11866648

15. Chen V, Ning H, Allen N, Kershaw K, Khan S, Lloyd-Jones DM, et al. Lifetime risks for hypertension by contemporary guidelines in African American and white men and women. JAMA Cardiology 2019; 4(5): 455-9. https://doi.org/10.1001/jamacardio.2019.0 529

PMid: 30916719 PMCid: PMC6537805 
16. Wati DK, Yuliyatni PCD, Dinata IMK, Nilawati GAP, Widiana IGR, Sutawan IBR, et al. Child blood pressure profile in Bali, Indonesia. Open Access Macedonian Journal of Medical Sciences 2019; 7(12): 1962-7.

https://doi.org/10.3889/oamjms.2019.466

PMid: 31406537 PMCid: PMC6684429

17. Bank Indonesia. Bali Province economic report. Denpasar: Bali Province Representative Office of Bank Indonesia; 2019. Available from:

https://www.bi.go.id/id/publikasi/kajianekonomiregional/bali/Documents/Laporan Perekonomian Provinsi Bali Agustus 2019.pdf

18. Indonesian Ministry of Education and Culture. Master data for primary and secondary school [Internet]. 2019. Available from:

https://referensi.data.kemdikbud.go.id/ind ex11.php?kode $=220000 \&$ level $=1$

19. Sjarif DR, Nasar SS, Devaera Y, Tanjung CF. Indonesian Pediatric Society recommendation: Pediatric nutrition care. Jakarta: Division of Nutrition and Metabolic Disease in Indonesian Pediatric Society; 2011.

20. Flynn JT, Kaelber DC, Baker-Smith CM, Blowey D, Carroll AE, Daniels SR, et al. Clinical practice guideline for screening and management of high blood pressure in children and adolescents. Pediatrics 2017; 140(3).

https://doi.org/10.1542/peds.2017-3035

PMid: 29192011

21. National Institute of Health Research and Development. Basic health research report of Bali Province in 2018. Basic Health Research Team 2018, editor. Jakarta: Publishing House for the National Institute of Health Research and Development; 2019. Available from:

https://www.litbang.kemkes.go.id/laporanriset-kesehatan-dasar-riskesdas/

22. World Health Organization. Prevalence of obesity [Internet]. The Global Health Observatory. 2016. Available from: https://www.who.int/data/gho/data/indicat ors/indicator-details/GHO/prevalence-ofobesity
23. Nehus E, Mitsnefes M. Childhood obesity and the metabolic syndrome. Pediatric Clinics of North America 2019; 66(1):3143.

https://doi.org/10.1016/j.pcl.2018.08.004 PMid: 30454749

24. Indonesian Presidential Regulation No. 42 of 2013 on the National Movement on Acceleration of Nutrition Improvement. Indonesia; 2013. Available from: https://peraturan.bpk.go.id/Home/Details/4 1412/perpres-no-42-tahun-2013

25. Ogden CL, Carroll MD, Kit BK, Flegal KM. Prevalence of childhood and adult obesity in the United States, 2011-2012. JAMA 2014; 311(8): 806-14.

https://doi.org/10.1001/jama.2014.732

PMid: 24570244 PMCid: PMC4770258

26. Parker ED, Sinaiko AR, Kharbanda EO, Margolis KL, Daley MF, Trower NK, et al. Change in weight status and development of hypertension. Pediatrics 2016; 137(3): 20151662.

https://doi.org/10.1542/peds.2015-1662

PMid: 26908707 PMCid: PMC4771125

27. Chorin E, Hassidim A, Hartal M, Havakuk $\mathrm{O}$, Flint $\mathrm{N}$, Ziv-Baran $\mathrm{T}$, et al. Trends in adolescents obesity and the association between BMI and blood pressure: A crosssectional study in 714,922 healthy teenagers. American Journal of Hypertension 2015; 28(9): 1157-63. https://doi.org/10.1093/ajh/hpv007 PMid: 25736450

28. Xi B, Zong X, Kelishadi R, Litwin M, Hong YM, Poh BK, et al. International waist circumference percentile cutoffs for central obesity in children and adolescents aged 6 to 18 years. Journal of Clinical Endocrinology and Metabolism 2020; 105(4): E1569-83.

https://doi.org/10.1210/clinem/dgaa578 PMid: 32997789

29. Cheah WL, Chang CT, Hazmi H, Kho GWF. Using anthropometric indicator to identify hypertension in adolescents: A study in Sarawak, Malaysia. International Journal of Hypertension 2018;2018. Available from:

https://www.ncbi.nlm.nih.gov/pmc/articles /PMC6093054/ 
30. Sukhonthachit P, Aekplakorn W, Hudthagosol C, Sirikulchayanonta C. The association between obesity and blood pressure in Thai public school children. BMC Public Health 2014; 14(1): 729. https://doi.org/10.1186/1471-2458-14-729 PMid: 25034700 PMCid: PMC4223408
31. Rachmi CN, Li M, Alison Baur L. Overweight and obesity in Indonesia: Prevalence and risk factors - a literature review. Public Health 2017; 147:20-9.

https://doi.org/10.1016/j.puhe.2017.02.002 PMid: 28404492 